\title{
Editorial: Cyberpsychology has more submissions and citations
}

\author{
Lenka Dedkova', David Smahel ${ }^{2}$, Kristian Daneback $^{3}$ \\ 1,2 Faculty of Social Studies, Masaryk University, Brno, Czech Republic \\ ${ }^{3}$ Department of Social Work, University of Gothenburg, Gothenburg, Sweden
}

Dear researchers, colleagues, and readers interested in research on the internet and technology,

We are happy to present the second issue of the 10th volume of Cyberpsychology: Journal of Psychosocial Research on Cyberspace. This issue consists of six articles that utilize various methodological designs and analytical approaches: three quantitative surveys, an experiment accompanied by questionnaires, semi-structured interviews utilizing thematic analysis, and a content analysis of social media posts. The issue is also spread geographically with contributions from Europe (the United Kingdom, Germany, and Finland), the United States, and Thailand. In the editorial, we will briefly introduce each of these articles and then present our journal's statistics, including a summary of last year's submissions and the review process, and our current position in the Scopus database.

In the first article in this issue, Michael Glüer and Arnold Lohaus examine the impact of using social networking sites on the quality of German preadolescent and adolescent offline friendships. They found that the overall friendship quality and strength (with one selected friend) does not differ for those who use and do not use social networking sites. However, those with an SNS account discussed personal information, such as secrets and personal problems, with their offline friend more often than those without an account. Moreover, the authors compared the reported quality of predominantly online and predominantly offline friendships and found that the offline ones are described more positively than the online ones. For both types of friendships, being female, meeting initially offline, and having a higher frequency of contact were associated with higher friendship quality.

The second article, which is by Gina Roussos and John Dovidio, experimentally assesses the effect of playing SPENT, an online interactive game that simulates living in poverty, on attitudes toward poor. In the first of two studies, directly playing the game and observing another person playing the game produced greater empathic concern as opposed to playing a control game, but only the observation condition led participants to report more support for government funded anti-poverty policies and decreased their belief that poverty is personally controllable. The authors suggest that the effect of playing SPENT on attitudes toward the poor and beliefs about controllability may be moderated by a belief in meritocracy, and they assess these assumption in their second study. The results showed (among other things) a significant effect of playing SPENT upon those low in meritocracy: playing SPENT led to more negative attitudes toward the poor when compared to playing a control game. For those high in meritocracy, the game did not have an effect; participants reported consistent relatively negative attitudes toward the poor. Together, the studies in this article problematize the desired effect of similar games on social attitudes.

The next article, by Karmpaul Singh and colleagues, deals with how people with high health anxiety use the internet to search for health-related information. The authors conducted 20 interviews with highly anxious students and used a thematic analysis to examine the resulting data. The findings are organized chronologically by different stages of the searching process, from before the actual search, throughout the search, and to after 
searching. The study provides rich data about the participants' motivation, the searching process, the evaluation of the information obtained, and the outcomes of the search. The authors conclude that health-related internet use has the potential to maintain health anxiety, but, in some cases, may also contribute to the reduction of people's health concerns.

In the fourth article of this issue, Sarah-Rose Marcus explores the similarities and differences in the social media content of the pro-anorectic and fat-acceptance communities. Based on a content analysis of 800 Instagram posts, she focuses on the construction of their members' social identity and the provision of social support. The author points out that in both communities, indicators of the same tactics can be found, from reinforcing affiliation within the community, through enhancing the self-esteem of members, to separation from outsiders. The article includes many informative excerpts from the data and provides novel insights into the problems of body image and social media.

The next article, which is by Atte Oksanen and colleagues, also focuses partly on eating disorders, specifically on websites devoted to thinness, but it adds other harm-advocating sites for pro-suicidal and self-injury. The study utilizes a four-country sample (the United States, the United Kingdom, Germany, and Finland) of young internet users (aged 15 to 30) to examine the cross-cultural as well as the individual factors related to visiting such websites. Overall, the results showed that those who face more difficulties in their lives are at a higher risk to access sites which may further foster their unhealthy behavior patterns. Regarding country differences, the German sample reported the lowest level of exposure to harm-advocating websites. The authors speculate about the possible effect of language: there are simply more English websites than German ones. They also note that, relative to other countries, Germany has lower suicide rates in general; therefore, the behavioral patterns on the internet may be caused by other, culturally specific reasons.

In the last article of this issue, Peerayuth Charoensukmongkol focuses on the relations between selfie-liking and selected personal characteristics: narcissism, attention seeking, self-centered behavior, and loneliness among students at a Thai university. The results showed a positive association between selfie-liking and all of the examined characteristics: those who reported a higher score on selfie-liking were also more narcissistic and lonely, and they had more pronounced self-centered and attention seeking behavior. The study is thus in line with the other studies that link similar characteristics to selfies that were conducted in a Western context.

\section{Cyberpsychology in 2015: Increased Number of Submissions and Faster Decisions}

The increasing strength of the journal is supported by the increasing amount of submissions - we got about one third more submissions for regular issues in 2015 than in 2014. We published 10 articles in the two regular issues and 11 in two special issues. The acceptance rate for regular issues last year was about 10\%, which is $5 \%$ lower than the previous year. This is mostly due to the higher rate of direct rejects: almost half of the submissions were rejected by the editors in the past year without external review. The main reasons for editorial rejection in our journal can be found in one of our older editorials "How to increase probability of manuscript acceptance". Despite being written two years ago, the main reasons have stayed the same.

Submissions (N)

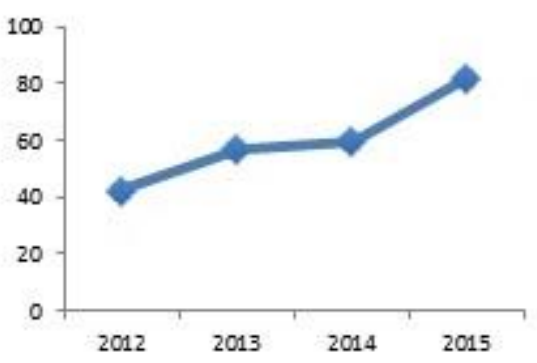

Acceptance rates (\%)

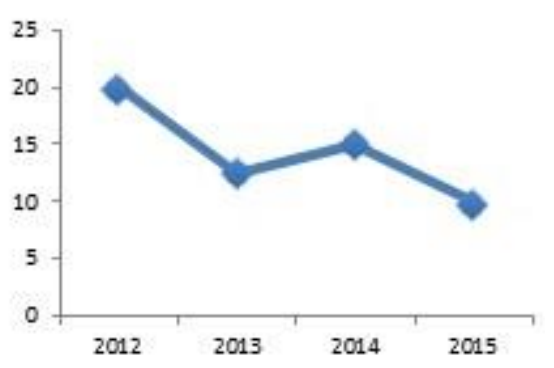

Cyberpsychology's regular issues over last four years. Amount of submissions and percentage of accepted manuscripts in each year. 
Additional good news is that the time for an editorial rejection was shorter in 2015 than a year ago - on average, we needed less than two weeks to reject an article. As expected, the external review process itself was slower we needed an average of 165 days to make decisions after reviews in 2015 (as calculated from the submission date to the decision date).

Because we have more submissions and more published articles, we are currently preparing a new editorial management system. An updated web page for the journal will provide a new and fresh display for the articles. We hope this big change will be beneficial for all interested parties - authors, reviewers, editors, and readers.

\section{New Statistics from Scopus: More Citations and More Articles}

Our journal has been part of Scopus since 2012. The journal is currently categorized in the subject area "Psychology" and the subject category "Psychology (miscellaneous)". As an interdisciplinary journal, we aim to add more subject categories, such as "Communication" and "Human-Computer Interaction".

The box below shows the development of our SJR (Scimago Journal \& Country Rank) index, Cites per document, and Total cites in 2015. You can see details of our journal results at this web page.

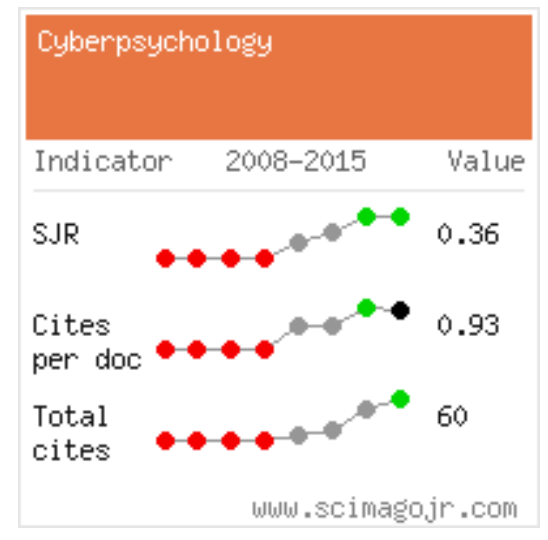

The SJR index of the journal remained almost the same as in 2014: we are the No. 118 journal out of 220 in our category. What is important is that our total number of citations is still increasing (from 45 to 60 in last three years). Our "Citations per document" index in the last two years (which is constructed similarly to the Impact Factor on the Web of Science) also remained mostly unchanged - 0.933 in 2015 . This index represents the average citation per article in a two-year period and it is computed by dividing the number of citations by the number of published articles. This index remained similar to the previous year; although we had about $25 \%$ more citations, we also published more articles in the relevant years (from 41 to 61 published articles). We can thus say that our journal is getting bigger and stronger.

We wish you nice summer and we will be happy to meet you personally at the 14th "Cyberspace" Conference in Brno on Nov. 25-26, 2016 (see http://cyberspace.muni.cz). We will be honored to discuss your possible manuscripts, and also all of the issues concerning the research of Cyberspace!

All the best,

Lenka Dedkova, David Smahel, and Kristian Daneback 


\section{Issue Content}

Article 1:

Editorial: Cyberpsychology has more submissions and citations

Lenka Dedkova, David Smahel and Kristian Daneback

doi: 10.5817/CP2016-2-1

Article 2:

Participation in social network sites: Associations with the quality of offline and online friendships in German preadolescents and adolescents

Michael Glüer and Arnold Lohaus

doi: 10.5817/CP2016-2-2

Article 3:

Playing below the poverty line: Investigating an online game as a way to reduce prejudice toward the poor

Gina Roussos and John F. Dovidio

doi: 10.5817/CP2016-2-3

Article 4:

Health anxiety and Internet use: A thematic analysis

Karmpaul Singh, John R. E. Fox and Richard J. Brown

doi: 10.5817/CP2016-2-4

Article 5:

Thinspiration vs. thicksperation: Comparing pro-anorexic and fat acceptance image posts on a photosharing site

Sarah-Rose Marcus

doi: 10.5817/CP2016-2-5

Article 6:

Young people who access harm-advocating online content: A four-country survey

Atte Oksanen, Matti Näsi, Jaana Minkkinen, Teo Keipi, Markus Kaakinen and Pekka Räsänen

doi: 10.5817/CP2016-2-6

Article 7:

Exploring personal characteristics associated with selfie-liking

Peerayuth Charoensukmongkol

doi: 10.5817/CP2016-2-7

\section{About Journal}

The 'Cyberpsychology: Journal of Psychosocial Research on Cyberspace' is a web-based, peer-reviewed scholarly journal. The first peer-reviewed issue was published in September 2007. The journal is focused on social science research about cyberspace. It brings psychosocial reflections of the impact of the Internet on people and society. The journal is interdisciplinary, publishing works written by scholars of psychology, media studies, communication science, sociology, political science, nursing, ICT security, organizational psychology and also other disciplines with relevance to psychosocial aspects of cyberspace. The journal accepts original research articles, as well as theoretical studies and research meta-analyses. Proposals for special issues are also welcomed. 
The journal is indexed with SCOPUS, ERIH PLUS, EBSCO Academic Search Complete, the Directory of Open Access Journals and the Czech Database of Scientific Journals.

The articles in Cyberpsychology: Journal of Psychosocial Research on Cyberspace are open access articles licensed under the terms of the Creative Commons Attribution Non-Commercial License which permits unrestricted, noncommercial use, distribution and reproduction in any medium, provided the work is properly cited.

\section{Editor}

Prof. David Smahel, M.Sc. et Ph.D., Faculty of Social Studies, Masaryk University, Czech Republic E-mail: smahel(at)fss.muni.cz

\section{Associate Editor}

Prof. Kristian Daneback, Ph.D., University of Gothenburg, Sweden

E-mail: kristian.daneback(at)socwork.gu.se

\section{Managing Editor}

Lenka Dedkova, Ph.D., Faculty of Social Studies, Masaryk University, Czech Republic

E-mail: Idedkova(at)fss.muni.cz

\section{Editorial Board}

Prof. Kaveri Subrahmanyam, Ph.D., California State University, Los Angeles, USA

Prof. Herbert Hrachovec, Ph.D., University of Vienna, Austria

Prof. Dr. Micheline Frenette, Universite de Montreal, Canada

Prof. Alexander E. Voiskounsky, Ph.D., Lomonosov Moscow State University, Russia

Prof. Michael W. Ross, Ph.D., DrMedSc, MPH, MPHEd, University of Texas, Houston, USA

Prof. Petr Macek, CSc., Masaryk University, Czech Republic

Prof. Olle Findahl, World Internet Institute, Sweden

Prof. Jochen Peter, Ph.D., University of Amsterdam, Netherlands

Prof. Veronika Kalmus, Ph.D., University of Tartu, Estonia

Prof. Joshua Fogel, Ph.D., Brooklyn College of the City University of New York, USA

Prof. Gustavo S. Mesch, Ph.D., University of Haifa, Israel

Prof. Lelia Green, Ph.D., Edith Cowan University, Australia

Prof. Michel Walrave, Ph.D., University of Antwerp, Belgium

Michelle Wright, Ph.D., Masaryk University, Czech Republic

Václav Štětka, Ph.D., Charles University, Czech Republic

Andra Siibak, Ph.D., University of Tartu, Estonia

Adjunct Prof. Birgit U. Stetina, Ph.D., University of Vienna, Austria

Lukas Blinka, Ph.D., Masaryk University, Czech Republic

\section{Advisory Board}

Prof. Bente Traen, Ph.D., University of Oslo, Norway

Prof. Charles Ess, Ph.D., University of Oslo, Norway

Prof. Dr. Ilse Kryspin-Exner, University of Vienna, Austria

Prof. PhDr. Jan Jirák, Ph.D., Charles University, Czech Republic

Prof. Vasja Vehovar, Ph.D., University of Ljubljana, Slovenia

Prof. Larry D. Rosen, Ph.D., California State University, USA

Prof. Patricia M. Greenfield, Ph.D., University of California, USA

Prof. Peter K Smith, University of London, England

Prof. Nicola Döring, Ilmenau University of Technology, Germany 
Prof. Kimberly Young, Ph.D., St. Bonaventure University, USA

Prof. Jos de Haan, Ph.D., Erasmus University, Netherlands

Prof. Zbyněk Vybíral, Ph.D, Masaryk University, Czech Republic

Prof. Monica Whitty, Ph.D., University of Leicester, UK

Prof. Alistair Duff, Ph.D., Edinburgh Napier University, Scotland

Assoc. Prof. Alfred Choi, Ph.D., Nanyang Technological University, Singapore

Prof. Thurasamy Ramayah, Universiti Sains Malaysia, Malaysia

Assoc. Prof. Neil Coulson, Ph.D., The University of Nottingham, UK

Assoc. Prof. Kenneth C. C. Yang, Ph.D., University of Texas at El Paso, USA

Assoc. Prof. Sun Sun Lim, Ph.D., National University of Singapore, Singapore

Prof. Sameer Hinduja, Ph.D., Florida Atlantic University, USA

Assoc. Prof. Jana Horáková, Ph.D., Masaryk University, Czech Republic

Assoc. Prof. Radim Polčák, Ph.D., Masaryk University, Czech Republic

Assoc. Prof. Pille Pruulmann-Vengerfeldt, Ph.D., University of Tartu, Estonia

Assist. Prof. Alexander Schouten, Ph.D., Tilburg University, Netherlands

Assist. Prof. Ewa S. Callahan, Ph.D., Quinnipiac University, USA

Assist. Prof. Regina van den Eijnden, Ph.D., Utrecht University, Netherlands

PhDr. Ing. Petr Soukup, Charles University, Czech Republic

Janis Wolak, Ph.D., University of New Hampshire, USA

Francesca Romana Seganti, Ph.D., Sapienza University of Rome, Italy

Jeff Gavin, Ph.D., University of Bath, UK

Hana Macháčková, Ph.D., Masaryk University, Czech Republic

Michael Fenichel, Ph.D., New York, USA

Leslie Haddon, Ph.D., London School of Economics, UK

\section{Publisher}

Masaryk University, Faculty of Social Studies

Jostova 10, 60200 Brno

Czech Republic

\section{Publication Schedule}

Four issues per year: two regular issues (in July and December) plus two special issues (between regular issues) 


\section{About authors}

Lenka Dedkova, Ph.D., is a researcher at the Institute for Research of Children, Youth and Family (Masaryk university, Brno, Czech republic) and a member of Interdisciplinary Research Team on Internet and Society (IRTIS) which researches social-psychological implications of the internet and technology. Her research interests include cyberbullying and meeting online strangers, with focus on children and adolescents, but she's also interested in online security behavior and social networking sites. Lenka also works as managing editor of Cyberpsychology: Journal of Psychosocial Research on Cyberspace.

David Smahel, Ph.D. is the Professor at the Institute of Children, Youth and Family Research, Masaryk University, the Czech Republic. He is member of Interdisciplinary Research Team on Internet and Society (IRTIS) which researches social-psychological implications of the internet and technology. Current research focuses on adolescents' and adults' internet use, the online risks of children and adolescents, the construction of online identities and virtual relationships, and online addictive behavior. He is editor of Cyberpsychology: Journal of Psychosocial Research on Cyberspace and has co-authored book Digital Youth: The Role of Media in Development (Springer, 2011). Smahel also published in several international journals such as Developmental Psychology, Cyberpsychology \& Behavior, Zeitschrift für Psychologie, European Journal of Developmental Psychology and others. He is also author of several book chapters, such as in Encyclopedia of Cyber Behavior, Encyclopedia of Adolescence, Internet Addiction: A Handbook and Guide to Evaluation and Treatment, Gesundheit und Neue Medien etc.

Kristian Daneback, Ph.D. is the Professor of Social Work at the University of Gothenburg, Sweden and in the Faculty of Social Studies at Masaryk University in Brno, Czech Republic. His main field of research is sexuality and in particular internet sexuality, but he is also interested in other internet related phenomena such as parenthood and the internet, cyberbullying, and how the internet can be used to collect qualitative and quantitative data. Daneback has published his research in several well known international journals such as Archives of Sexual Behavior, Cyberpsychology, Behavior, \& Social Networking, Journal of Sexual and Relationship Therapy, Journal of Bisexuality, and Sexual Addiction \& Compulsivity. In addition, he is a reviewer for journals such as Journal of Sex Research, Journal of Computer Mediated Communication, Pediatrics, Sex Roles, and Sexual Reproduction \& Health Care. Currently he serves as the Associated Editor of Cyberpsychology: Journal of Psychosocial Research on Cyberspace and is a Board Member of the Open Journal of Communication and ISRN Family Medicine. Daneback is also a member of the International Academy of Sex Research and the Association of Internet Researchers. 